\title{
Higiene oral en escolares de 6 años de la Parroquia Rural Baños-Ecuador
}

\author{
Oral hygiene in schools of 6 years of age of the Baños Rural Parish - Ecuador
}

Lucero Ulloa Santiago a, León Vélez Eleonor ${ }^{1 b}$, Calle Jara Felipe ${ }^{1 c}$, Katherine Correa Carrera $2 a d$

\section{RESUMEN}

Objetivo Determinar el grado de higiene oral en escolares de 6 años de la parroquia rural Baños. Materiales y métodos El estudio tuvo un enfoque cuantitativo descriptivo. Se utilizaron los datos de la recolección digital en el programa Epi INFO. La muestra estuvo constituida por 198 escolares de 6 años, de los cuales 94 escolares son de sexo femenino que representa el $47 \%$ de la muestra y 104 escolares son de sexo masculino que representa el $53 \%$ de la muestra. Resultados Los resultados obtenidos demostraron que el $64 \%$ de los niños de la parroquia Baños presentaron un Índice de Higiene Oral Simplificado igual a 0,9, un índice de placa bacteriana igual a 0,8 y el índice de cálculo de 0,1 . De los centros educativos de la parroquia, seis de ellos presentaron una "Buena" higiene oral y 3 presentaron una higiene oral "Regular". Conclusiones Los escolares de 6 años de la parroquia Baños presentan una buena higiene oral, no encontrándose diferencia entre ambos géneros.

PALABRAS CLAVES: Placa Dental; Higiene Bucal; Cepillado Dental. Fuente: DeCS BIREME)

\section{ABSTRACT}

Objective To determine the degree of oral hygiene in 6-year-old schoolchildren in the rural parish of Baños. Materials and Methods The study had a descriptive quantitative approach. Use the data from the digital collection in the Epi INFO program. The sample consisted of 1986 -year-old schoolchildren, of which 94 are female students representing $47 \%$ of the sample and 104 male schoolchildren representing $53 \%$ of the sample. Results The results obtained showed that the children of the parish Baths indicated $64 \%$ in a Simplified Oral Hygiene Index equal to 0.9, a bacterial plaque index equal to 0.8 and the calculation index of 0.1 . The educational centers of the parish six of them visualize a "good" oral hygiene and 3 manifestations a "regular" oral hygiene. Conclusions The 6-year-old schoolchildren of the Baños parish have good oral hygiene, with no difference between the two genders.

KEY WORDS: Dental Plaque, Oral Hygiene, Dental Brushing. (Source: MeSH NLM)

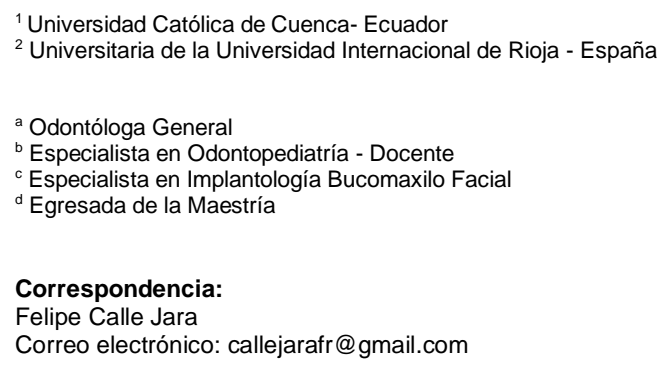

Este es un artículo Open Access distribuido bajo la licencia Creative Commons Atribución-No ComercialCompartir Igual 4.0

\section{(ㅇ)(○)}

Citar como: Lucero S. León E. Calle F. Higiene oral en escolares de 6 años de la Parroquia Rural Baños-Ecuador KIRU. 2020; 17(1): 10-15. https://doi.org/10.24265/kiru.2020.v17n1.02 


\section{INTRODUCCIÓN}

La placa dentobacteriana es considerada una de las principales causas que provocan la aparición de patologías bucodentales como caries dental y enfermedad periodontal (1), los niños son principalmente los más afectados, razón por la cual creemos que estas dos enfermedades antes citadas son prevenibles, si existe un buen autocuidado de la salud bucal (2).

Dentro de la placa dental, se encuentra una complejidad de bacterias entre 200 a 300 especies, siendo el microorganismo colonizador el Streptococcus Sanguis e inmediatamente adhiriéndose el Actinomyces Viscosus, además se pueden encontrar la Neisseria sp, Streptococcus Mitis Streptococcus Oralis, entre otros ${ }^{(3)}$.

Entre la parte orgánica de la placa dental tenemos en la saliva las glucoproteínas de las bacterias, los polisacáridos, la albúmina y las grasas; en cambio, el fósforo, calcio y otros minerales se encuentran en la parte inorgánica de placa dental ${ }^{(4)}$. Los efectos nocivos de los microorganismos se producen por los productos metabólicos, estos modifican los carbohidratos fermentables formando ácidos, a su vez estos ácidos disuelven los tejidos dentarios mineralizados, estos en contacto con el diente, por un tiempo prolongado, provocan una descalcificación produciendo caries dental ${ }^{(5)}$.

Greene y Vermillion crean el Índice de Higiene Oral Simplificado (IHOS), siendo un método rápido para evaluar la cantidad de detritus y placa ${ }^{(2)}$. Este índice revisa un total de seis superficies, el cálculo dental está conformado por compuestos orgánicos entre estos polisacáridos, proteínas, células epiteliales descamadas, leucocitos, entre otros; se encuentran sales inorgánicas sobre todo de fosfato cálcico, fosfato magnésico y carbonato cálcico en un 70 a $90 \%{ }^{(7)}$. El componente inorgánico principal es el fosfato de calcio, además presenta formas cristalinas de hidroxiapatita en un $58 \%$, fosfato octocálcico $12 \%$, bruxita $9 \%$, la whitlokita de magnesio $21 \%(5,6)$ Para evitar la formación de placa bacteria y cálculo, es indispensable una higiene bucal siendo esta un factor importante para la salud integral de la persona en cualquier etapa de su vida ${ }^{(2)}$.

Hoy en día, existen programas orientados para mantener una higiene bucal saludable, previniendo el desarrollo de patologías bucodentales más severas ${ }^{(2)}$. Por ello, es importante determinar el nivel del Índice de Higiene Oral Simplificado Comunitario en los escolares de 6 años de la parroquia rural Baños.

\section{MATERIALES Y MÉTODOS}

El estudio presenta un enfoque cuantitativo descriptivo, se utilizaron los datos de la recolección digital en el programa Epi INFO. La muestra estuvo constituida por 198 escolares de 6 años de la parroquia Baños de la ciudad de Cuenca-Ecuador, de los cuales 94 escolares son de sexo femenino que representa el $47 \%$ de la muestra y 104 escolares son de sexo masculino que representa el $53 \%$ de la muestra.

Se utilizó el índice IHOS de Greene y Vermillon para dientes permanentes y deciduos, buscando describir cuantitativamente el problema que existió en los escolares. Se calculó este índice utilizando la fórmula IHOS = Índice de Detritus + Índice de Cálculo. Para este índice de higiene oral se requiere evaluar: 2 dientes anteriores y 4 posteriores completamente erupcionados, en la arcada superior se evalúan las superficies vestibulares de los primeros molares superiores derecho e izquierdo y del incisivo central superior derecho ${ }^{(3)}$. En la arcada inferior, se evalúan las superficies linguales del primer molar inferior izquierdo, incisivo inferior derecho, primer molar inferior derecho ${ }^{(3)}$. En caso de no estar presente la pieza dental mencionada, se tomará el diente vecino, considerando que no se tomará otro diente en las piezas temporales, se excluirá de la evaluación a piezas posteriores y anteriores ausentes 0 con presencia de restauraciones con coronas en los dientes permanentes ${ }^{(3)}$.

Los criterios para establecer el grado de (DI-S) son 0 = no hay residuos 0 manchas, $1=$ los residuos 0 cálculo no cubre más de un tercio de la superficie dentaria, 2 = los residuos o cálculo cubren más de un tercio de la superficie, pero no más de dos tercios de la superficie dentaria, 3 = los residuos o cálculo cubren más de 2 tercios de la superficie dentaria expuesta ${ }^{(8)}$.

En cambio, los criterios para establecer el grado de (Cl-S) son 0 = no existe sarro presente, $1=$ cálculo supragingival que cubre no más de una tercera parte de la superficie dental expuesta, $2=$ sarro supragingival que cubre más de un tercio, pero menos de las dos terceras partes de la superficie dental expuesta o hay presencia de vetas individuales de cálculo subgingival alrededor de la porción cervical del diente o de ambos. 3 = sarro supragingival que cubre más de dos tercios de la superficie dental expuesta o hay una banda gruesa continua de cálculo subgingival alrededor de la parte cervical del diente o ambos ${ }^{(8)}$

El promedio para el (Cl-S) y (DI-S) se realiza por persona. $\mathrm{Cl}-\mathrm{S}$ = Suma del (Cl-S) dividido entre el número de dientes examinados. DI-S = Suma del (DI$S$ dividido entre el número de dientes examinados ${ }^{(3)}$. La obtención del IHOS, se realiza mediante la suma de Cl-S Y DI-S. Greene y Vermillion proponen una 
escala para la evaluación de la higiene oral del individuo ${ }^{(5)}$. Una calificación de "excelente" con una puntuación de 0, "buena" con una puntuación 0,1 y 1,2; "regular" con una puntuación de 1,3 y 3,0; y "mala" con una puntuación de 3,1 y $6,0^{(5)}$.

Luego se realizó el mismo cálculo, pero agrupando por sexo, se cuantificó en cada individuo la cantidad de placa y cálculo dental para analizar el IHOS y se reportó como promedio poblacional general y por sexos. Estos valores fueron presentados en porcentajes, el presente estudio no implicó conflictos bioéticos.

\section{RESULTADOS}

De 198 escolares de 6 años, 94 corresponden al sexo femenino que representa el $47 \%$ y 104 escolares al sexo masculino que representa el $53 \%$. (Figura 1). Para el sexo femenino el 2,5 representa el máximo de IPB con un promedio de IPB de 0,79. Para el sexo masculino el 2,16 representa el máximo de IPB con un promedio de 0,83. Dando como resultado que la parroquia Baños presente un 2,5 como máximo de IPB, con un promedio de 0,81 ; encontrándose una desviación estándar de 0,55 no siendo estadísticamente significativa (Figura 2).

Para el sexo femenino, el 2,5 representa el máximo de IPC con un promedio de IPC de 0,16. Para el sexo masculino, el 1,66 es el máximo de IPC con un promedio de IPC de 0,11. Dando como resultado que la parroquia baños presente un 2,5 como el máximo de IPC, con un promedio de 0,13; con una desviación estándar de 0,36 no siendo estadísticamente significativa (Figura 3).

Se encontró un IHOS Bueno (61)31\% para el sexo femenino y el (66)33\% para el sexo masculino. IHOS Excelente en un 18\%, correspondiendo el (16)8\% al sexo femenino y el (19) $10 \%$ al sexo masculino. IHOS Regular en un $17 \%$, correspondiendo el (15)8\% al sexo femenino y el (18)9 \% al sexo masculino. IHOS Malo en un $2 \%$, correspondiendo el (2) $1 \%$ al sexo femenino y el (1) $1 \%$ al sexo masculino. (Figura 4) En general, se determinó un IHOS Bueno en un $64 \%$, IHOS Excelente en un $18 \%$, IHOS Regular en un 17 $\%$ y IHOS Malo en un $2 \%$ (Figura 5 ).

Según el centro educativo, la escuela Honorato Vázquez presenta un máximo de IHOS de 5 con un promedio de IHOS de 0,84; la escuela Segundo Espinoza presenta un máximo de IHOS de 3,66 con un promedio de IHOS de 1,27; la escuela Medardo Neira presenta un máximo de IHOS de 3,33 con un promedio de IHOS de 1,75; la escuela Agustín Carrión presenta un máximo de IHOS de 3 con un promedio de IHOS de 1,47; la escuela Cornelio Crespo presenta un máximo de IHOS de 3 con un promedio de IHOS de 1,11 ; la escuela Alfonso Carrión presenta un máximo de IHOS de 2,83 con un promedio de IHOS de 0,91; la escuela Agustín Cuesta presenta un máximo de IHOS de 2,5 con un promedio de IHOS de 1,05; la escuela Enriqueta Cordero presenta un máximo de IHOS de 2,16 con un promedio de IHOS de 0,66; la escuela Joel Monroy presenta un máximo de IHOS de 2 con un promedio de IHOS de 1,07. Encontrándose una desviación estándar de 0,78 estadísticamente significativa.

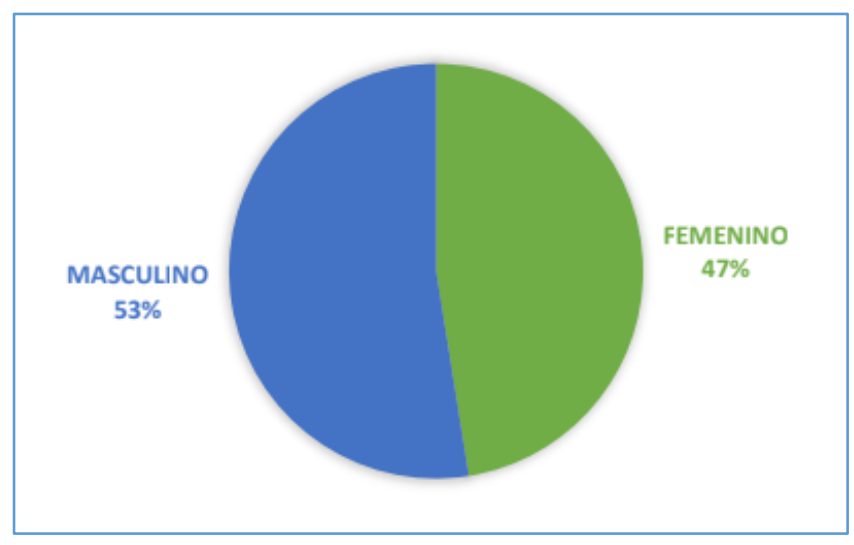

Figura 1. Distribución de la muestra según el sexo.

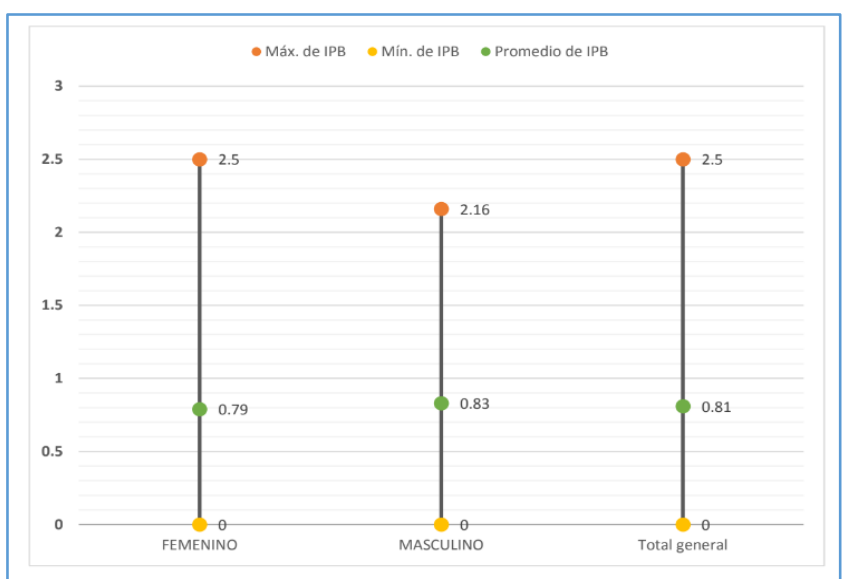

Figura 2. Índice de Placa Blanda según el sexo en los escolares de 6 años.

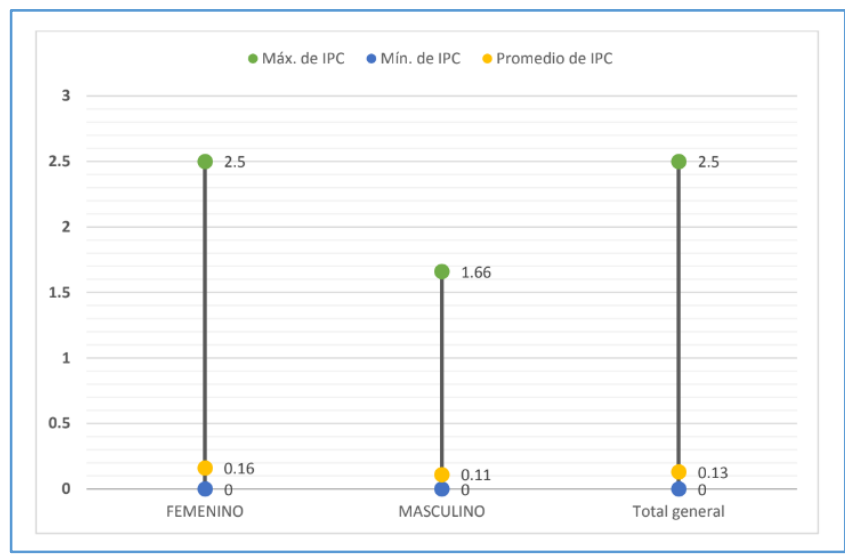

Figura 3: Índice de Placa Calcificada según el sexo. 


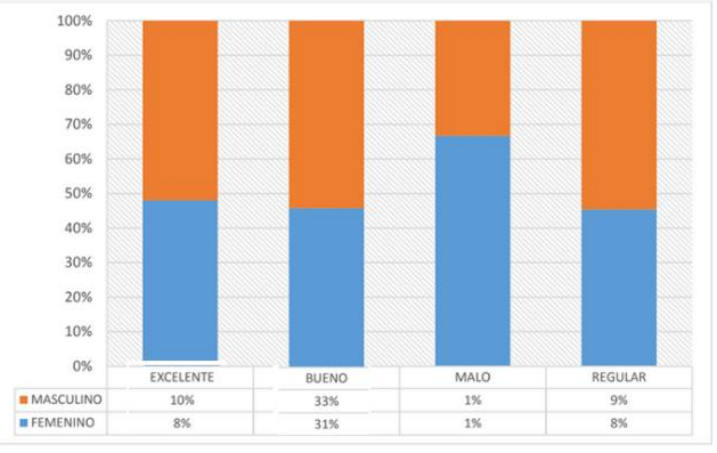

Figura 4. Índice de Higiene Oral Simplificado de acuerdo al

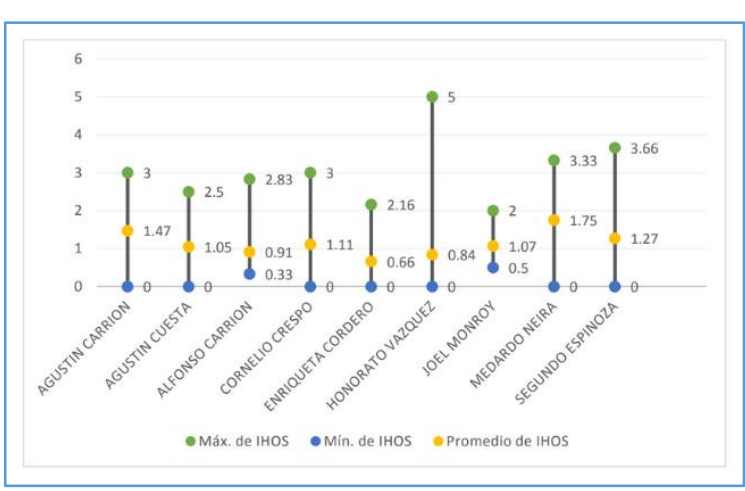

Figura 5. Clasificación del Índice de Higiene Oral Simplificado.

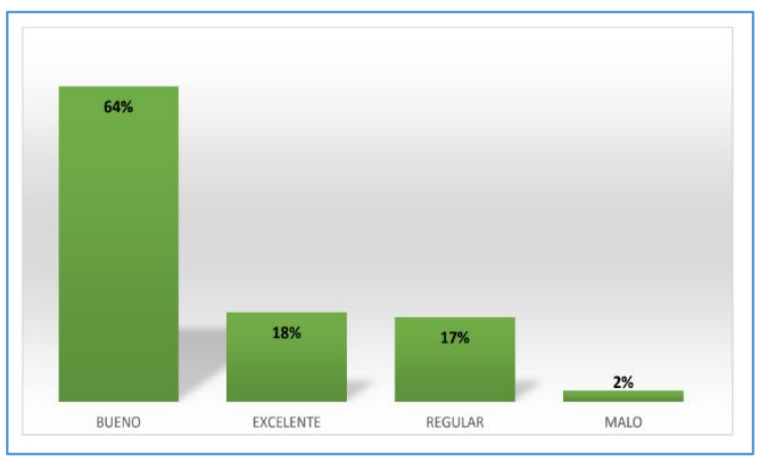

Figura 6. Índice de Higiene Oral Simplificado por centro educativo de la parroquia Baños.

\section{DISCUSIÓN}

La presente investigación realizada en la parroquia Baños del cantón Cuenca-Ecuador dio como resultado que los escolares de 6 años de edad presentan un promedio de IHOS de 0,95; lo cual, considerando la escala propuesta por Greene y Vermillion, da como resultado que los niños de la parroquia presentan una calificación de "buena" higiene oral. Moses ${ }^{(9)}$, en el año 2013, realizó un estudio con 25 escolares de 6 años en el distrito de Paucarpata (Perú), donde los niños presentan una calificación "mala" higiene oral; Mediavilla ${ }^{(2)}$, en el año 2011 en Quito, estudió el IHOS en escolares de ambos géneros de la fundación Remar entre la edad de 6 a 12 años, indicando como resultado que los niños presentan una higiene oral "regular". En los estudios, se encuentran diferentes criterios en el índice de higiene bucal. En la parroquia Baños se presenta el índice bueno debido a que los niños en su mayoría no tienen un cepillado de sus dientes de manera regular o no poseen un cepillo dental. En Perú, los niños presentan una mala higiene por motivo que los mismos tienen un desconocimiento total de cómo cepillarse los dientes; y, en los niños de Quito, se da la higiene regular porque los niños son en su mayoría de 6 años y poseen un conocimiento bajo de cómo mantener una higiene oral adecuada y presentan una menor destreza en cómo cepillarse los dientes. Por lo cual, se deben generar medidas preventivas y promoción de la salud oral en esta edad para evitar la aparición de patologías bucodentales severas.

Gómez ${ }^{(6)}$ en México realizó una investigación para determinar el índice de higiene oral de 195 estudiantes de la Universidad de Veracruzana, donde el 81,5\% presenta un Índice de higiene oral "Bueno", de igual manera el estudio realizado por el autor Corchuelo (10) a 83 niños que cursan el quinto año de primaria en Colombia donde el 80 \% presenta un Índice de higiene oral "Bueno", lo cual comparando con el estudio realizado en la parroquia Baños encontramos similares resultados debido a que los niños de esta parroquia presentan en un $64 \%$ el índice de higiene oral "Bueno". Por este motivo lo recomendable para mantener una higiene bucal saludable es utilizar la seda dental, los enjuagues bucales y el cepillado de 3 veces al día sobre todo en la noche (6). En Quito Mediavilla ${ }^{(2)}$ realizó un estudio a los escolares de 6 a 12 años de la fundación Remar, en el que se encontró que existe un promedio de placa blanda "regular" y un promedio de índice de cálculo dentario "excelente", mientras que en la investigación realizada en la parroquia Baños se presenta un promedio "bajo" de placa blanda y placa calcificada, en Quito se presenta esos promedios de placa por motivo de que la muestra estuvo conformada por niños que oscilan entre la edad de 6 a 12 años y en el presente estudio de la parroquia Baños se encuentran solo niños de 6 años. No obstante, estas investigaciones nos indican que sin importar la edad se encuentra los 2 tipos de placa en los infantes. En el 2013 Moses ${ }^{(9)}$ mediante su estudio en Perú determina que una institución pública del distrito de Ate Vitarte presenta IHOS "regular"; en su estudio Merada (11) da como resultado un IHOS "bueno" para la escuela pública Himmelman, no se encontraron diferencias con este estudio porque de los 9 centros educativos públicos de la parroquia Baños 6 presentan un IHOS "bueno" y 3 presentan un IHOS "regular". Estos resultados se observan debido a que en la institución pública de Perú los niños de 6 años no presentan una adecuada técnica de cepillado, en la 
escuela Himmelman los niños solo se cepillan una vez al día y visitan al odontólogo solo cuando presentan dolor. En la parroquia Baños, los centros educativos no cuentan con un odontólogo de cabecera para que haga una revisión periódica a los niños y, debido al factor socioeconómico, los padres no hacen que los niños visiten a un odontólogo particular. Por ello, se requiere un trabajo en conjunto de los padres, maestros y profesionales de salud para que la población infantil adquiera y mantenga una higiene oral adecuada.

- Se necesita más estudios para determinar el tipo de bacteria presente en la placa dental que se da con mayor frecuencia en los niños de 6 años de la parroquia Baños para investigaciones posteriores. En la placa dental encontramos de 200 a 300 especies, entre los microorganismos se encuentra principalmente el Streptococcus Sanguis y Actinomices Viscosus ${ }^{(3)}$.

- Determinar tipo de alimentación de los escolares de 6 años de la par

oquia Baños, ya que se relaciona con la parte orgánica de la placa, pues en la saliva se encuentran las glucoproteínas de las bacterias, los polisacáridos, albumina y grasas. En cambio, los fosfatos, calcio y otros minerales los encontramos en la parte inorgánica (4).

- Investigar la frecuencia del cepillado dental de escolares de la parroquia Baños, ya que al segundo día después de su formación se inicia la mineralización de la placa bacteriana ${ }^{(5)}$.

- Enfocarse en las escuelas que presentaron un IHOS bajo y regular, con charlas, medidas de autocuidado e investigación (frecuencia de cepillado, alimentación)

- Realización de monitorización longitudinal para comparar si las medidas tomadas han servido para la mejora de la salud bucal de estos sujetos.

Se determinó mediante la escala Greene y Vermillion que el Índice de Higiene Oral Simplificado en los escolares de la parroquia Baños fue de 0,9, el valor del Índice de Placa Blanda fue de 0,8, también se comprobó que el Índice de Placa Calcificada fue de 0,1 . Es importante recalcar que la higiene dental en el grupo de estudio fue considerablemente buena.

Contribuciones de autoría: LUS, LVE y CJF diseñaron el estudio, recopilaron, analizaron los datos, redactaron y aprobaron el manuscrito.

Fuente de financiamiento: Autofinanciado.

Conflicto de intereses: Los autores declararon no tener conflictos de interés.

\section{REFERENCIAS}

1. Caridad C. El pH, flujo Salival y capacidad buffer en relación a la formación de la placa dental. Biblat.unam.mx [Internet]. 2016. [citado 23 de noviembre de 2016] Disponible en: http://biblat.unam.mx/es/revista/odouscientifica/articulo/el-ph-flujo-salival-y-capacidadbuffer-en-relacion-a-la-formacion-de-la-placadental.

2. Criollo M, Iván F. Determinación del índice de higiene oral simplificado en niños y niñas de 6 a 12 años de edad de la Fundación Remar-Quito, en el mes de julio del año 2011. 2011 [citado 23 de noviembre de 2016]; Disponible en: http://www.dspace.uce.edu.ec/handle/25000/669.

3. Jara V. Las técnicas de cepillado dental y su relación con la presencia de placa bacteriana en los niños de tercer año de educación básica de la escuela fiscal Laura Carbo de Ayora del cantón Guamote, provincia de Chimborazo, en el período septiembre 2013 - febrero 2014. Riobamba; [Internet]. 2014 [citado 23 de noviembre de 2016]. Disponible en: http://dspace.unach.edu.ec/bitstream/51000/195/1/ UNACH-EC-ODONT-20140019.pdf

4. Martínez F., Programa de prevención y control de placa dentobacteriana en niños de 7 a 8 años de edad de la primaria "Alfonso Arroyo Flores de Poza Rica, Ver, México; [Internet], 2011. [citado 23 de noviembre de 2016]. Disponible en: http://cdigital.uv.mx/bitstream/123456789/30904/1/ BadilloMtz.pdf

5. Mera, L. Índice de higiene oral simplificado comparativo entre niños y niñas de 6 a 12 años de edad, de la escuela fiscal "Himmelman" y la unidad educativa particular "Héroes del Cenepa" del cantón Cayambe de la provincia de Pichincha, en el período 2010-2011" Quito; [Internet]. 2011. [citado 23 de noviembre de 2016]. Disponible en: http://www.dspace.uce.edu.ec/bitstream/25000/86 3/4/TUCE-0015-22.pdf.

6. Ríos, N, García, M. Determinación de los Índices CPO-D e IHOS en estudiantes de la Universidad Veracruzana, México. Rev Chil Salud Pública. [Internet].; 16(1):26-31, 2012 [citado 23 de noviembre de 2016]. Disponible en http://www.revistasaludpublica.uchile.cl/index.php/ RCSP/article/view/18609.

7. Casillas A. Tipos de depósitos dentales: Placa bacteriana y cálculo dental. [Internet]. 2011 [citado 23 de noviembre de 2016]. Disponible en: http://www.seindor.com/publicacionesdidacticas.co $\mathrm{m} /$ hemeroteca/articulo/01803 9/articulo-pdf.

8. Criollo F. Determinación del Índice de Higiene Oral Simplificado en niños y niñas de 6 a 12 años de edad de la Fundación Remar-Quito. Julio.2011.

9. Moses, A. Caries dental asociada al índice de higiene oral simplificado en niños de 6 a 12 años de una institución educativa pública del distrito de ATE - VITARTE en el año 2013, Perú [Internet]. 2014 [citado 23 de noviembre de 2016]. Disponible en: http://repositorioacademico.upc.edu.pe/upc/bitstre am/10757/322242/1/Moses AA.pdf

10. Corchuelo J. Sensibilidad y especificidad de un índice de higiene oral de uso comunitario. Colombia Médica, [Internet] 2011 [citado 23 de noviembre de 2016]. 
Disponible en: http://www.redalyc.org/articulo.oa?id=2832154300 5

11. Rodríguez R. Hábitos de higiene bucal y su influencia sobre la frecuencia de caries dental. Acta Pediátrica de México [Internet] 2008. [citado 23 de noviembre de 2016]. Disponible en: http://www.medigraphic.com/pdfs/actpedmex/apm2008/apm081e.pdf. 